\title{
Una espiritualidad para luchar por la justicia desde la perspectiva de Ignacio de Loyola
}

\author{
Rodolfo Cardenal
}

El Congreso de Teología, organizado por el Departamento de Teología de la Universidad Centroamericana "José Simeón Cañas" para conmemorar los treinta años del martirio de Mons. Óscar A. Romero, es lugar apropiado para presentar y comentar la obra de Dean Brackley, Espiritualidad para la solidaridad. Nuevas perspectivas ignacianas (UCA Editores, 2010), porque contribuye a enriquecer la espiritualidad de la liberación. Intentaré presentar y comentar el libro al mismo tiempo. Aun cuando toda presentación siempre es una interpretación, me esforzaré por ser fiel a su pensamiento, al mismo tiempo que comento sus aportes más sobresalientes.

En particular, me interesa destacar la novedad de esta obra para la espiritualidad ignaciana y también para la espiritualidad de la liberación. Dean Brackley consigue, desde su experiencia personal y desde su perspectiva teológica y espiritual, encarnar los Ejercicios espirituales de Ignacio de Loyola en el mundo actual, algo que en la década de 1970, Ignacio Ellacuría ya había sugerido. Así, pues, este libro pertenece a la corriente de la teología de la liberación. La perspectiva histórica y liberadora no es un añadido, ni una superposición a la experiencia espiritual ignaciana, porque su estructura interna la reclama.

\section{Un testimonio de fe actualizado e histórico}

Espiritualidad para la solidaridad. Nuevas perspectivas ignacianas es un libro que no deja indiferente, aun cuando se desconozca o no se haya pasado por la experiencia de los Ejercicios espirituales de Ignacio de Loyola. Sus páginas tocan fibras profundas de la realidad personal y social, que interpelan a quien las lee. En efecto, la claridad y la propiedad con las que Dean Brackley explora la realidad humana pueden ayudar a quienes se encuentran en búsqueda o a quienes luchan por alcanzar la plenitud. 
No deja de ser curioso que la primera sorprendida por este libro haya sido su editora (Ellen Calmus). El contenido del texto la cambió de tal manera que se ha tomado la libertad de colocar un prólogo de su propia cosecha, dirigido a escépticos o agnósticos como ella, a quienes invita a tomar con interés una obra que puede ayudarlos a encontrar lo que buscan con tanto tesón. La editora habla desde su experiencia. Tomó el libro sin mayor interés, pero el estilo directo y agudo de Brackley la impulsó a leerlo de corrido. A medida que avanzaba, éste la llevó desde su problemática personal hasta Ignacio de Loyola y su experiencia del Dios de Jesús. De esta manera, descubrió que el libro podía ayudar a otras personas a encontrar respuesta a las cuestiones que tanto les preocupan, así como también podía ayudarlas a tomar decisiones importantes, para las cuales nadie se encuentra preparado. Constata con admiración que Ignacio de Loyola se habría anticipado varios siglos a la psicología moderna en el descubrimiento de las dificultades para comprenderse sí mismo, para superar los fracasos y las frustraciones, y para decidir aun en contra de los proyectos personales o para emprender caminos contrarios a los previstos. Otra de las características del libro que sorprende a la editora es la habilidad de Brackley para discutir las ideas religiosas en el contexto de la modernidad y la postmodernidad. Al final, ella misma se convierte al Dios de Jesús. Aun cuando no puede garantizar este resultado a otras personas, sí les asegura que sus páginas pueden abrirles un horizonte hasta ahora desconocido.

Cuando hace ya algunos años, leí por primera vez este libro, en la edición inglesa, animé a Brackley a traducirlo al español para publicarlo en UCA Editores, porque pensé que haría mucho bien a mucha gente. En él pueden encontrar un comienzo de respuesta quienes sufren las consecuencias de la desarticulación cultural del cristianismo occidental. Gracias a su capacidad para comunicar ideas complejas, Brackley consigue exponer el genio de Ignacio de Loyola en el contexto de la modernidad y la postmodernidad. De esta forma, ofrece una alternativa válida y provocadora a quienes buscan una espiritualidad para llenar el vacío que los angustia y atormenta. Sobre todo a quienes se lanzan a la caza de experiencias novedosas, incluso esotéricas, más allá del cristianismo. Ante un Dios experimentado como ausencia, Brackley ofrece un Dios cercano e interesado en las personas y su futuro. No es, pues, necesario acudir a las innumerables ofertas del mercado religioso actual. A quienes desconfían de una institución eclesiástica que ya no orienta, ni integra, ni expresa la experiencia religiosa personal, Brackley les presenta un camino para aprender a confiar en el Dios de Jesús —o en lo que él llama "el Santo Misterio", para evitar susceptibilidades inútiles-. En este sentido, Espiritualidad para la solidaridad responde al deseo profundamente sentido por encontrar respuesta satisfactoria a las cuestiones clave de la vida humana. Esta es una obra de espiritualidad que abre horizontes nuevos a quienes buscan un sentido para su vida. 
Espiritualidad para la solidaridad es un libro para un tiempo de crisis de Dios y, en consecuencia, también de crisis de humanidad. La inseguridad provocada por estas crisis suscita la proliferación de tendencias gnósticas, cuyas incontables posibilidades ofrecen respuestas al margen de las confesiones religiosas y de la institucionalidad eclesiástica. Por lo tanto, la religiosidad no ha desaparecido, pues las expresiones religiosas, incluso místicas, son muchísimas, pero sin Dios. Estas corrientes afirman de manera tan absoluta la individualidad y la interioridad que llegan a identificar a la persona con Dios o absorberla en Dios y a Dios en la persona. Los mitos gnósticos, clericales y anticlericales, sofisticados y elitistas, pero siempre vulgarizaciones, se encargan de explicar cómo la salvación se encuentra en la interioridad individual, en la autorrealización y el individualismo. Esta religión no puede fallar, porque su dios está arraigado en el yo -aunque al mismo tiempo está desterrado más allá del cosmos, en algún lugar infinitamente remoto-. En todo caso, desvincula la salvación de la historia, con lo cual hace desaparecer la dimensión histórica de la fe y Dios deja de ser Dios. El antiguo ideal de cambiar el mundo es reemplazado por la transformación individual. El compromiso político es sustituido por la experiencia mística y la emoción efervescente. La responsabilidad ética se diluye en una enorme variedad de valores, todos ellos relativos y válidos, pero sin posibilidad de verificación. No hay visión de futuro, ni utopía. Lo único que importa es la verdad del instante.

En cambio, Espiritualidad para la solidaridad deja a Dios ser Dios y, por lo tanto, mantiene la relación entre salvación e historia. No niega la individualidad, ni la interioridad de la persona, pero enfatiza su apertura a los demás, a la trascendencia y a la utopía. Sin desconocer el profundo deseo personal y social de salvación, señala que esta pasa por los pueblos crucificados y la solidaridad. La tentación real de refugiarse en la intimidad y la emoción es contrarrestada por la dimensión práctica de la fe cristiana, que exige cierta reciedumbre y madurez. La necesidad de salvar la historia retorna a la ética y a la acción eficaz como criterios de verificación imprescindibles de una verdadera experiencia de Dios. Finalmente, señala un camino viable para conquistar la libertad para amar $-\mathrm{y}$ para dejarse amar, una dimensión del amor que suele ser pasada por alto- . La transformación del mundo necesita de personas libres para amar y para dejarse amar.

Este libro no es una simple introducción a los Ejercicios espirituales, sino una aproximación a la experiencia ignaciana, desde la realidad histórica, personal y social. Dean Brackley recrea la experiencia de Ignacio de Loyola desde la seria crisis de identidad y de fe de su juventud, desde sus experiencias en el Bronx (Nueva York) y Perú y El Salvador, en concreto, Jayaque. Asimismo, recoge impresionantes testimonios de grandes creyentes del siglo XX. Estos relatos y testimonios introducen los diversos temas $\mathrm{y}$, así, los actualizan y los hacen comprensibles a la mentalidad contemporánea. El punto de partida de cada tema 
no es, pues, la revelación, sino estas experiencias humanas, porque se trata de una búsqueda personal, válida tanto para creyentes como para no creyentes. En este sentido, Brackley no repite el texto de los Ejercicios espirituales con palabras modernas, sino que recrea su intuición fundamental, y al hacerlo, la interpreta. Distingue con rigor lo esencial de lo circunstancial, que responde más al contexto cultural donde surge el texto de Ignacio de Loyola. Va más allá de los Ejercicios e incluye sus intuiciones más maduras sobre la vida espiritual. Apoyado en los avances exegéticos y teológicos y en los debates recientes sobre las cuestiones cruciales de la espiritualidad ignaciana, desentraña la intuición fundamental. Especial cuidado presta a las formulaciones extrañas a la sensibilidad contemporánea, sobre todo al no creyente, un interlocutor presente en todas las páginas del libro. Por eso, Brackley habla de la trascendencia sin mistificación, descodifica el lenguaje teológico e introduce de forma gradual la oración. Sabe, por experiencia propia, cuando él mismo fue agnóstico, que muchos pueden sacar provecho del pensamiento ignaciano. Sin embargo, no por eso renuncia a los símbolos religiosos, pues también está convencido de que el "Santo Misterio" compenetra nuestras vidas. Prescindir de ellos y de la realidad trascendente a la que apuntan implicaría dejar fuera una dimensión importante de la realidad, tanto más cuando intenta romper el encerramiento en la inmanencia y en la intimidad individualista para abrir a la trascendencia y la utopía, a la sociedad y la solidaridad. Al final, sin proponérselo, en cada página se vislumbra la personalidad de Dean Brackley, que describe la vida como "bailar con Dios".

Así, pues, Espiritualidad para la solidaridad es un testimonio de fe, al igual que los Ejercicios espirituales. Pero es un testimonio de fe actualizado, en el sentido que este concepto tiene para Zubiri y Ellacuría. De la misma manera que Ignacio de Loyola historiza la palabra de Dios en los Ejercicios espirituales, Brackley historiza a estos últimos. Textos como los Ejercicios espirituales solo cobran vida cuando son leídos e interpretados desde la realidad histórica. Aquí radica la novedad y la relevancia de Espiritualidad para la solidaridad. En efecto, aparte de explicar la rica intuición ignaciana, muestra cómo Dios habla hoy de muchas maneras, porque todavía no ha dicho algo fundamental para la vida. Cuando se deja escuchar, esa palabra es novedad y promesa. No puede ser de otra manera, porque al Dios de Jesús sólo se accede desde la razón histórica, el instrumento que, según Ellacuría, mejor y más plenamente puede captarlo. Sin duda, se puede acceder a él desde la creación, pero de forma limitada. Únicamente en la verdad del proceso histórico como un todo es posible acceder a Dios. Dicho de otra manera, la creación adquiere pleno significado y totalidad en la historia, de la misma manera que ésta carece de realidad, excepto referida a la naturaleza (Ignacio Ellacuría).

No obstante lo anterior, la novedad del libro no radica es su lograda relectura de la experiencia ignaciana más genuina. Otros se han adelantado a Brackley en este empeño. La novedad de Espiritualidad para la solidaridad está en que 
ofrece una alternativa para superar la crisis de humanidad actual. Una crisis directamente relacionada con la crisis de fe en el Dios de Jesús. Por lo tanto, aquí la espiritualidad es entendida como un modo de vivir. Al creyente le proporciona pistas para vivir su relación con Dios inmerso en el mundo - "vivir en el Espíritu"-. Al cristiano, además, le muestra cómo seguir a Jesucristo. Al no creyente le presenta un método para avanzar hacia la plenitud humana, a través de la exploración de su interioridad individual, sus talentos, sus deseos y sus aspiraciones. Este libro no ofrece soluciones, sino caminos para recorrer la vida con sentido humano y creyente. Por eso, el mismo Brackley recomienda al lector ser discreto, es decir, apropiarse de aquello que lo ilumine, lo sane y le abra al futuro de la promesa de la vida plena. Pero como la lectura no suple los ejercicios espirituales, lo más recomendable es hacer esa experiencia. En cualquier caso, este es un excelente libro que, sin duda, hará mucho bien a quienes, creyentes o no, luchan por alcanzar la plena realización humana.

\section{Contemplativo en la lucha por la justicia}

Espiritualidad para la solidaridad ofrece una posibilidad real para superar la crisis de humanidad y de Dios, porque sitúa en la realidad histórica una experiencia que, por lo general, suele ser presentada desde una perspectiva exclusivamente personal. El título del libro expresa con antelación y de manera inequívoca la centralidad de esa realidad para la experiencia espiritual. Sin desconocer que los Ejercicios espirituales se concentran en la persona y su relación con Dios, Brackley enfatiza la dimensión social en la cual transcurre esa relación. Por lo tanto, el tema central de esta obra de espiritualidad no es sólo la salvación de la persona, sino también, y de manera intrínseca, la salvación de la historia. En este sentido, Espiritualidad para la solidaridad es un libro de espiritualidad de y para la liberación.

Desde las primeras páginas, Brackley toma una postura radical ante la injusticia. Afirma que es imposible ser humano y cristiano sin asumir la injusticia como una responsabilidad personal. Por eso, además de enfrentar el mal, o el pecado personal, insiste en la necesidad de confrontar con la misma intensidad y seriedad el mal social. De lo contrario, el amor se vuelve abstracto y la acción, ineficaz. La realidad histórica, a la que también hay que contemplar, está marcada por el signo de la cruz. No es un signo abstracto, sino histórico, porque se trata de los pueblos crucificados de los que habla Ignacio Ellacuría. Ellos constituyen el signo de todos los tiempos. Desde sus cruces, esos crucificados nos descubren la vocación a la solidaridad y, por lo tanto, el sentido profundo de la vida humana. Brackley confiesa que ellos lo ayudaron a redescubrir el cristianismo y que, desde entonces, han marcado su peregrinar. Así, la perspectiva solidaria, de liberación y liberadora, resulta ser un antídoto eficaz contra las tendencias subjetivistas, interioristas o intensamente emotivas, que acentúan la conversión personal, en contextos abstractos y, por lo tanto, ajena al compromiso con el cambio social. 
El proceso espiritual parte de la necesidad de salvación, es decir, de la conversión sincera del pecado. Pero Brackley enfatiza que no podemos olvidar que el pecado más fehaciente, masivo y mortífero es el despojo de los pobres - "el gran pecado de todos los tiempos, el núcleo del pecado del mundo"-, que ha crucificado y todavía crucifica a los pueblos. Por eso, el pecado personal, raíz de todo pecado, es sólo una dimensión de la salvación. La otra es "el pecado del mundo... un pecado que es más que la suma de los pecados individuales", que debe ser asumido con la misma gravedad y seriedad que el personal. La verdad de esta realidad empecatada se descubre en la contemplación. Por eso, contemplar, una dimensión fundamental de la oración, es contrario a huir del mundo. Bien entendida, la espiritualidad se enfrenta con la realidad, penetra en ella y se deja penetrar por ella - hacerse cargo, encargarse y cargar con la realidad, según la formulación de Ignacio Ellacuría-.

Hoy en día, el pecado del mundo, históricamente considerado, cobra cuerpo en la sociedad liberal, que "trivializa el mal y, en la práctica, lo niega". Está a favor "de la vida sin estar en contra de la muerte". El liberalismo, denuncia Brackley, proclama que la felicidad está en el consumo, el mercado y la elección de los gobernantes. El único obstáculo que se interpone en el camino a la felicidad serían los terroristas y los narcotraficantes, los desechos tóxicos y el calentamiento global. El cristianismo no cuestiona la existencia del pecado, pero no suele considerar sus "consecuencias cognitivas" más letales - encubrir la injusticia y considerar a unas personas más importantes que otras-. El individualismo dominante no facilita el descubrimiento de la profundidad y la extensión de un pecado que sabe ocultarse en "las sonrisas cálidas, las plataformas políticas, la retórica piadosa y la propaganda publicitaria", así como también en "un montón de virtudes... la libertad, el derecho de propiedad, la seguridad nacional y la religión", o en mentiras, más o menos intencionadas, que obnubilan la mente. Es necesario desenmascarar ese pecado, porque aleja de los pobres y los oprimidos, los únicos que pueden abrir los ojos al engaño del mundo. Las víctimas, en su pasión y su muerte, son las únicas que pueden mostrar la crueldad del mundo e impedir caer en la ilusión de la salvación individualista o en los engaños mundanos. Por eso, la perspectiva profética no es un añadido a las meditaciones tradicionales de los Ejercicios espirituales, sino un elemento determinante. La religión, nos recuerda Brackley, solo libera cuando es profética, es decir, cuando denuncia el abuso, defiende al débil y anuncia una utopía creíble. La contemplación descubre la verdad del pecado, pero la transformación y la liberación no se producen por el conocimiento interno, sino por medio de una acción eficaz.

Las víctimas también son buena noticia, porque median el perdón incondicional, infinito y definitivo de Dios. Un perdón concedido no porque seamos buenos, sino porque Dios es bueno - "el Santo Misterio nos asedia desde fuera y desde dentro con un ofrecimiento permanente de perdón, pese a lo que hayamos hecho"- El perdón de Dios libera de los sentimientos de culpa y de 
los remordimientos por los pecados cometidos, así como también libera de la angustia provocada por los defectos y fallos personales. El sabernos aceptados por Dios tal como somos nos permite avanzar con seguridad hacia el encuentro con nosotros mismos y con Él. La experiencia de la misericordia de Dios humaniza de una manera tan radical que fuerza a hablar de un nuevo nacimiento. Los místicos hablan de enamoramiento. Ellacuría, de vivir como resucitados. En cualquier caso, una pasión nueva se apodera de quien acoge esa oferta de perdón. En efecto, quien vive como perdonado vive libre de angustias y abierto a los demás (conversión). La misericordia de Dios es una bella experiencia de amor y un motivo para la celebración, la alegría y la esperanza.

El perdón divino suscita la solidaridad. Brackley piensa que la contemplación de los estragos causados por la injusticia no solo debiera provocar "vergüenza y confusión", tal como Ignacio de Loyola espera, sino que, además, debiera abrir a la solidaridad con los pobres y las víctimas. La perspectiva tradicional, que atribuye a la penitencia ese mismo poder sanador y liberador, conduce al mismo sitio. Pero "la mejor penitencia", según Brackley, consiste en "responder al prójimo que tenga necesidad". El perdonado no permanece impasible ante el pecado del mundo. La paz y la alegría que el perdón de Dios trae están acompañadas de una llamada a participar en su tarea salvadora o liberadora.

La solidaridad con el sufrimiento de los crucificados abre otra posibilidad real de humanización. La tradición ha atribuido al sufrimiento un poder enorme de purificación. Durante dos mil años, la contemplación de la pasión de Jesús ha ayudado a los creyentes a soportar el dolor, a superar el temor y a enfrentar la tribulación. Sin embargo, la solidaridad introduce un matiz novedoso en esta perspectiva tradicional. Brackley no enfatiza el sufrimiento, porque no es bueno, ni deseable. Mucho menos aprecia el sufrimiento infligido a sí mismo. Sino que invita a colocarse al lado de quienes sufren. En concreto, llama a compartir el sufrimiento de los pueblos crucificados para así participar del mismo dolor de Dios. El dolor compartido es otra forma de ser solidario. Aunque no suprime el sufrimiento, la solidaridad ayuda a sobrellevarlo, sobre todo cuando impulsa a intentar bajar de la cruz a los crucificados. Pocas experiencias humanizan e inspiran tanto como el amor sufriente. Quienes sufren como Jesús comprenden mejor el sufrimiento por amor. Por lo tanto, la contemplación de la pasión y de la muerte de Jesús no solo proporciona un conocimiento mejor, un seguimiento más cercano y un amor mayor, sino que, además, debiera animar a intentar bajar de la cruz a los pueblos crucificados. Este ejercicio no solo fortalece contra la adversidad, sino que también ablanda el corazón, reúne los fragmentos dispersos del yo, centra y sana.

La perspectiva de la solidaridad de Brackley no interpreta la muerte de Jesús como expiación para aplacar la ira divina, sino como expresión máxima del amor divino. Dios "oculta" su divinidad para acercarse a la humanidad, incluso ahí 
donde es más vulnerable - en la humillación, la impotencia y el sufrimiento-. Dios sufre con la humanidad las consecuencias del pecado del mundo - la avaricia, el desprecio, la idolatría del poder y de la violencia, la adicción, la ceguera culpable, el rechazo al forastero y la denegación del perdón-. Esta manera de ser Dios cuestiona la idea tradicional de la divinidad. El poder divino no se manifiesta en obras portentosas, sino en ponerse a disposición de la humanidad para liberarla del pecado opresor. Es "la divinidad escondida" la que, de manera desconcertante, revela el poder divino en todo su esplendor. De la misma manera que la pasión y la muerte de Jesús muestran dónde encontrar a Dios, la pasión y muerte del inocente indican dónde encontrarlo en la actualidad. Por eso, Jesucristo sólo "se deja ver" por quienes han reconocido su divinidad escondida en su pasión y su muerte. Se "deja ver" a los pobres con espíritu y entre las víctimas de la injusticia y la violencia, a quienes da esperanza y anima a luchar para salvar el plan de la creación.

Intentar bajar a los crucificados de la cruz, impedir que la injusticia cause más estragos y defender a las víctimas del poder opresor suele ser conflictivo y desata la persecución y, no pocas veces, la muerte. Contrario a la idea predominante, Brackley defiende que el conflicto es parte del Evangelio y de la construcción del reino de Dios. Por lo tanto, en sí mismo, no es malo, ni debe ser evitado, ni tampoco suprimido. En consecuencia, el seguimiento de Jesús exige una espiritualidad para esos tiempos recios, la cual, según Brackley, se caracteriza por conservar la paz interior, en el conflicto y la persecución, por confiar en Dios, en la oscuridad y el abandono, por actuar con audacia, creatividad y en comunidad, y por amar a los enemigos.

Los Ejercicios espirituales culminan con la llamada "contemplación para alcanzar amor", una experiencia que Brackley considera en sí misma revolucionaria. Esta contemplación se propone experimentar el amor de Dios, por lo general, en las maravillas de la creación. La experiencia de ese amor suscita una respuesta agradecida. Ahora bien, no cualquier respuesta es válida, sino solo la determinación de servir al mundo. La gran novedad de Ignacio de Loyola estriba en afirmar que Dios puede ser encontrado en todas las cosas y en todas las actividades. El amor es concebido como actividad — "en todo amar y servir"- La proximidad con Dios es tal que la acción se vuelve contemplación, pues siempre lo encuentra. La intimidad con Dios facilita la comunicación, aun ahí donde ésta parece imposible. Esta meditación es una especie de Pentecostés, un tema ausente en los Ejercicios, al igual que el Espíritu Santo, mencionado sólo en seis lugares. Ignacio de Loyola no enfatiza su acción quizás para evitar una condena de la Inquisición por "alumbrado". De hecho, el cristianismo occidental aprecia poco la acción del Espíritu Santo.

La familiaridad con Dios también revoluciona el concepto de la oración. Contemplar es dejar que la realidad penetre y remueva la manera de sentir y de 
pensar. Hacer oración es ser realista. Dios habla desde el centro de la realidad personal e histórica. Cuando esta forma de orar se convierte en hábito, se proyecta en la acción y la transforma en contemplación. Ignacio de Loyola, por lo tanto, concibe la oración como contemplación en la acción. Tradicionalmente, la oración está asociada a la vida retirada, según un falso ideal monástico, que contrapone las figuras de Marta y María. Esta concepción valora el retiro y la contemplación con menoscabo de la acción transformadora del mundo o de la salvación de la historia. Por lo tanto, la oración contemplativa sería la medida de la santidad. Ignacio de Loyola, en cambio, rechaza como criterios de perfección la soledad y las largas horas de oración. Tampoco las considera como medio preferencial para la unión con Dios. Aun cuando la oración en soledad es siempre necesaria, no es lo ideal. La unión con Dios no ocurre en la oración, sino en la búsqueda y en la puesta en práctica de su voluntad. Se ora en la medida en que la contemplación influye en la acción. La radicalidad de esta propuesta consiste en permanecer en unión con Dios, en la vida diaria. Es la práctica del amor la que une a Dios, quien, a su vez, se hace presente en el amar.

No obstante, tal como señala Brackley, ese amor es histórico, porque el objeto de su actividad —o servicio por amor- es la liberación de los pobres y los oprimidos, y porque la gratitud es auténtica cuando la vida es experimentada no como algo dado, sino como una conquista cotidiana. En efecto, Dios se hace presente en toda acción buena, pero de manera especial y específicamente cristiana, en la acción histórica, que libera del pecado opresor y homicida y así da vida. Indudablemente, Dios se revela en la belleza de la creación - a lo cual suele contribuir el ambiente idílico de las casas de ejercicios-, pero sólo a quien también puede reconocerlo en los pobres y los oprimidos, porque ellos se colocan forzosamente en su presencia. Si no se es capaz de reconocerlo en la humanidad quebrantada, Él tampoco se deja ver en las maravillas naturales. Jesucristo sólo se "deja ver" cuando se ven las cruces históricas. Esto no es obvio, porque su crueldad impulsa a volver la mirada hacia el otro lado. La acción contemplativa que comunica la voluntad de Dios es la acción del seguimiento histórico. De esta manera, la liberación es el lugar privilegiado para la acción, que en su secularidad, transparenta la presencia y la acción del Dios salvador - "Dios se hace presente al hombre haciendo y el hombre hace presente a Dios y se hace presente a Dios haciendo" (Ellacuría)—.

Al igual que Ignacio de Loyola, Brackley también recomienda la oración breve y transida por los afanes de la vida entregada con generosidad —en contraposición a la oración prolongada y tranquila. Por eso, la mejor preparación para la oración, un recurso muy recomendado por Ignacio de Loyola, consiste en colocarse delante de los crucificados del mundo y dejar que ellos nos liberen de los prejuicios y nos interpelen sobre lo que haremos para bajarlos de la cruz. Este es un método eficaz para evitar las demandas de un amor abstracto. Así, pues, 
contraponer oración y acción es una artimaña teórica para huir de la historia y de sus reclamos de salvación. La oración es uno de los momentos de la acción. Es cuando la acción, en su modalidad cristiana, se capta a sí misma reflexivamente. Seguir a Jesús hoy, según Ellacuría, es ser contemplativo en la acción por la justicia, unido a Dios en la lucha por un mundo más justo.

A Dios, por lo tanto, lo encontramos en la actividad secular e histórica. En concreto, en las encrucijadas. Ahí donde se decide la vida y la muerte de la mayor parte de la humanidad. Dios siempre es Dios en y con la humanidad. Se hace presente en la persona en acción y la persona se hace presente a Dios y vuelve presente a Dios en la acción. Pero para ello es necesario estar libre de y tener libertad para entrar en comunicación con Él.

\section{Libres para la solidaridad y el amor}

Espiritualidad para la solidaridad, al igual que los Ejercicios espirituales, es un libro práctico. Ambos intentan ayudar a adoptar decisiones sabias y, por lo tanto, apuntan a la acción que se propone dar continuidad a la misión de Jesús. Así, pues, ninguno de estos libros es totalmente contemplativo, tal como pudiera pensarse a priori. Tampoco se mantienen en el reino de la pasividad. Sino que invitan a reformar la vida y a transformar la historia, en la línea del Reino de Dios. Esta dimensión práctica es necesaria para verificar la veracidad y la bondad de la elección. En definitiva, Espiritualidad para la solidaridad puede ser de mucha utilidad para el postmoderno interesado en descubrir su vocación personal.

A diferencia de las corrientes gnósticas, aquí la respuesta ética es obligatoria. De lo contrario, la responsabilidad se diluye en filantropía vaga e ineficaz. Redescubrir o retornar a la religiosidad sin compromiso ético es esnobismo. La derecha divina espiritualista, en concreto, comete la temeridad de obsesionarse con la búsqueda de experiencias nuevas y excitantes, que se agotan en sí mismas. Espiritualidad para la solidaridad, en cambio, anima a descubrir la vocación primaria al amor y a la solidaridad en los pueblos crucificados o en el sufrimiento de la humanidad. Ahora bien, ese descubrimiento no depende únicamente del esfuerzo humano. La iniciativa proviene de una llamada "suave y delicada", pero clara e inconfundible, por la cual Dios irrumpe en la vida de las personas. La contribución humana se da en un segundo momento, en la respuesta a esa invitación. Una respuesta que debe ser inmediata y personal, que compromete a toda la persona al mismo tiempo que la introduce en una nueva manera de vivir. Aunque, por lo general, esa llamada se deja escuchar en la juventud sin compromiso, no es un don reservado a unos cuantos privilegiados, sino que incluye a toda persona deseosa de hacer el bien. 
Antes, esta llamada se entendía como invitación a colaborar con la obra salvífica de Dios y con la misión de la Iglesia. Pero en la actualidad, advierte Brackley, solo es comprensible si es entendida como participación en la lucha para quitar el pecado del mundo y salvar la historia. En cualquier caso, la respuesta a la llamada de Dios es un desafío. Obstáculos de toda clase impiden que la buena disposición inicial se concrete en acciones salvíficas. Algunas veces, la respuesta es incompleta; otras veces, se malogra por completo. Los mejores proyectos con frecuencia arrojan realidades demoníacas. El espíritu de Jesús tiende a la libertad y la vida, pero el egoísmo innato empuja a la esclavitud y la muerte. La fantasía contemporánea - La guerra de las galaxias y El señor de los anillos - comparte esta visión dual de la vida y la historia, pero no saca sus consecuencias. Ignacio de Loyola, experimentado conocedor de la ambigüedad de la realidad humana, nos coloca ante esa alternativa con connotaciones religiosas - Jesucristo y Lucifer- Debemos escoger entre ellas, porque no solo son fuerzas que se excluyen, sino que, además, se encuentran enzarzadas en una constante y encarnizada lucha. En la llamada meditación de "las dos banderas", intenta ayudarnos a elegir la libertad y la vida en lugar de la perversión y la muerte.

Aun cuando esta meditación penetra en lo más recóndito de la persona, Brackley abre nuevas perspectivas desde la solidaridad. La decisión sobre el rumbo que tomará la vida no concierne únicamente a la persona, pues tanto una como la otra poseen dimensiones sociales e históricas. La trilogía "riquezas, honores y soberbia", en la que Ignacio de Loyola sintetiza de manera magistral la objetivación del pecado, también explica, según Brackley, el mundo capitalista y patriarcal. En la actualidad, el capitalismo exacerba el deseo universal de poseer bienes materiales y recompensa la codicia con mayor generosidad que en el pasado, cuando la posición social dependía de las relaciones familiares. Peor aún, fomenta la arrogancia, el desprecio a los demás, la ambición y la voluntad de poder, es decir, induce a la soberbia, cuya lógica empuja hacia arriba. El soberbio se coloca por encima de los demás y convierte en razón de su existencia alcanzar los primeros puestos de la jerarquía social. Por eso, desprecia y resiente a quienes se encuentran por encima de él y a quienes percibe como rivales. Entre más estrecha es la ruta del ascenso social, la lucha por escalar a los primeros lugares es más despiadada. La medida del éxito, y de lo humano, la dan quienes llegan a la cima. Ellos son quienes ejercen la autoridad y el poder, indispensables para la vida social, como dominación para contener a los fracasados y los débiles y para mantenerlos en la dependencia, la ignorancia y la desorganización. Esta dinámica social engendra y propaga la agresividad y la corrupción, pero, sobre todo, el miedo, la desconfianza y la supremacía. No obstante su naturaleza diabólica, la lógica de la soberbia es presentada como sentido común y atrapa por igual a hombres y mujeres, ganadores y perdedores sociales. No es, pues, fácil modificarla. 
La trilogía opuesta de "pobreza, oprobios y humildad" sintetiza la objetivación del bien, pues representa la respuesta de Jesús a las tentaciones del desierto, expresa el servicio y define la estructura de la liberación cristiana. En clave de solidaridad, estas fuerzas del bien empujan hacia abajo y desatan una dinámica alternativa a las fuerzas del mal. Según Brackley, la solidaridad es el criterio objetivo de la pobreza. La movilidad hacia abajo introduce en el mundo de los pobres, invita a asumir su causa y, en alguna medida, también su condición, incluidas la oscuridad, el malentendido y el desprecio. La superación del capitalismo no consiste en que los pobres sean ricos, sino en compartir los bienes comunes de la creación y en comprometerse con la transformación de este mundo injusto en otro distinto, de acuerdo a los valores del Reino de Dios. El compartir y el colaborar revierten la lógica de la movilidad hacia arriba y ofrecen una alternativa real para la competencia salvaje. La solidaridad también es el sentido social de la humildad, pues identifica con los despreciados por la soberbia, comparte con ellos el sufrimiento y prefiere la pobreza y el rechazo social. De esta manera, la humildad es el fundamento de la sociedad justa, donde la dignidad humana es reconocida con independencia de la posición social, pues todo es don de Dios y nada es mérito propio.

Las riquezas, los honores y la soberbia son tanto pecados como principios de pecado, es decir, constituyen la vida personal. Esta trilogía conduce a toda clase de vicios, a la comisión de toda clase de injusticias y a la justificación de cualquier conducta. La penetración diabólica es objetiva y universal y, por lo tanto, fácilmente reconocible, pese a su carácter teologal. Por el otro lado, la penetración de las fuerzas del bien - la pobreza, los oprobios y la humildad- también es objetiva y universal. En concreto, la humildad es una fuerza activa y transformadora. Piensa y actúa en grande, pues siempre busca el mayor bien posible, conoce su potencial y lo pone a producir en esa dirección, es espontáneamente generosa, capta las ironías de la vida con su profundo sentido del humor, no se pierde en trivialidades y es superior a la mezquindad. Sin embargo, Brackley pone en guardia contra las falsas ideas de la humildad. No debe confundirse con la negación de sí mismo, pues ésta fomenta el pecado de omisión y obstaculiza la acción creativa. Tampoco con el resentimiento, que niega la bondad y la autoridad interior y oculta los talentos. Paradójicamente, los oprimidos son quienes con mayor facilidad dudan de sí mismos y quienes tienden a refugiarse en la pasividad. Los poderosos, por el otro lado, resienten la dignidad de los débiles. Estas falsas humildades son una rémora para el reino de Dios, pues impiden seguir el impulso del Espíritu para hacer el bien.

La lucha librada por las fuerzas del bien contra las del mal es teologal y, al mismo tiempo, siempre es histórica. Por eso, es obligado tomar partido por una de ellas. Toda persona debe decidir si realiza su vida desde la solidaridad o desde la soberbia. Sin embargo, es muy común no decidir. A veces se sale del 
paso sin saber cómo se reacciona a la situación. No en vano, observa Brackley, la habilidad más importante de la vida es aprender a adoptar decisiones sabias. La meditación de "las dos banderas" intenta reclutar para luchar del lado de las fuerzas del bien y de la solidaridad y en contra de la soberbia y de las fuerzas diabólicas. Aparentemente, la soberbia no sería una alternativa, pero, en realidad, no es así. El deseo tan humano de seguridades suele conducir a la absolutización de los medios que controlan el entorno —el dinero, el poder, el armamento y el prestigio social-. Una vez absolutizados, esos medios se convierten en ídolos que esclavizan a sus devotos y les exigen sacrificar vida humanas, incluso la propia. Aun los medios más necesarios, aquellos que facilitan la vida y la vuelven más cómoda, pueden dominar a quien se descuida. La incertidumbre es el caldo de cultivo de la peor soberbia. La plenitud no depende de la posesión de bienes, en sí mismos, buenos y necesarios, sino del abandono en las manos de Dios. Entonces, la cuestión es cómo dar este paso de fe profunda y cómo tener seguridad de que ese abandono se ha consumado.

El abandono en las manos de Dios supone la liberación de los ídolos, las compulsiones y los apremios más refinados y socialmente más estructurados. Pero esa liberación no es algo dado de una vez por todas, sino que es una conquista permanente. A medida que se goza de libertad interior se es indiferente para percibir y asumir el bien más universal, aun cuando este parezca ser contrario a las propias inclinaciones. De nuevo Brackley advierte contra una falsa concepción de la indiferencia, que ni siquiera es cristiana. Ser indiferente no es impasibilidad estoica, ni supresión del deseo, tal como proclaman algunas corrientes religiosas orientales. La indiferencia no es tanto desprenderse de las cosas como disponibilidad para entregarse al amor - "una generosidad magnánima, una entrega en las manos de Dios"-. Es el más de la exigencia cristiana - "estar comprometido con tanta pasión y determinación, estar tan enamorado, que estamos dispuestos a sacrificar cualquier cosa, hasta la propia vida, por el fin supremo"-

El medio para avanzar con cierta seguridad hacia el abandono total en las manos de Dios es el discernimiento de los estados emocionales. Ignacio de Loyola descubrió que la consolación y la desolación son fuerzas emocionales sutiles y contagiosas, que surgen desde las profundidades de cada persona y que actúan a través de la personalidad, en especial, de la psicología y del entorno. No obstante su apariencia tan humana, son de origen trascendente, lo cual dificulta definir sus límites. La consolación está asociada con el bienestar, mientras que la desolación lo está con la depresión. La primera ilumina la inteligencia, sana la psicología y el cuerpo y, en definitiva, humaniza; mientras que la segunda se ceba en la debilidad moral y la neurosis para deshumanizar y destruir. El discernimiento es necesario porque la voluntad de Dios no se reduce a principios universales y porque el signo de los tiempos no es unívoco, sino que debe ser 
interpretado. Asimismo, el discernimiento permite reconocer la actuación de las fuerzas del mal y ayuda a resistir sus embestidas. Las artimañas de las fuerzas diabólicas son más sutiles cuanto más completa es la entrega a Dios.

Ignacio de Loyola plantea tres clases de discernimiento. En la primera, la acción del Espíritu no deja dudas sobre cuál es la voluntad de Dios. En la segunda, se examinan las consolaciones y desolaciones. Y en la última, se recurre al análisis racional. La espiritualidad ignaciana ha privilegiado la segunda clase de discernimiento, complementada con la tercera, porque la primera siempre ha suscitado desconfianza. De esta manera, la consolación, a través de la cual el Espíritu inspira audacia, fortalece en la lucha y el fracaso, e infunde alegría y paz interior, sería el criterio fundamental para decidir. Ni el discernimiento ni, por lo tanto, la voluntad de Dios, recuerda Brackley, están reservados a una elite espiritual. Ambos están al alcance de cualquier persona, dispuesta a descubrir esa voluntad y a dejarse llevar por el impulso del Espíritu. La convicción de haber descubierto la voluntad divina se fundamenta en la fe en la bondad de Dios y en su deseo de comunicar esa buena noticia a la humanidad. Pero la voluntad de Dios no es un dato dado de una vez para siempre, sino que cambia, de acuerdo a las circunstancias históricas y personales. Por lo tanto, el discernimiento debe ser una actividad constante.

Dean Brackley enfatiza que el principio hermenéutico de los Ejercicios espirituales de Ignacio de Loyola es la realidad histórica, porque el Dios de Jesús es inaccesible al margen de la salvación de la historia. Cuando la justicia sea realidad, "vendrá tu reino" de la vida y las nuevas relaciones sociales, y de la liberación de la pobreza, del hambre y del llanto. El camino que conduce a la realización humana plena pasa, pues, por la opción por los pobres. En definitiva, ser recibido "bajo la bandera de Cristo", el tema central de la espiritualidad ignaciana, significa, según Brackley, solidarizarse con los pobres y oprimidos, y, por consiguiente, rechazar la riqueza y optar por la pobreza material y el desprecio que ellos experimentan. "Ser puestos con el Hijo", la meta de la meditación de "las dos banderas", es ser colocados ahí donde el Hijo dijo que estaría, entre los pobres y los oprimidos. "Alabar, hacer reverencia y servir a Dios" en la actualidad es, por consiguiente, "el servicio de la fe y la promoción de la justicia". La tarea a la cual Mons. Romero y los mártires de la UCA consagraron sus vidas y por la cual las entregaron con generosidad total.

Panamá, Managua y San Salvador, febrero-mayo de 2010. 